\title{
Resting-State Glutamate and GABA Concentrations Predict Task-Induced Deactivation in the Default Mode Network
}

\author{
Yuzheng $\mathrm{Hu},{ }^{\star} \mathrm{Xi}$ Chen,${ }^{\star}$ Hong $\mathrm{Gu},{ }^{\star}$ and Yihong Yang \\ Neuroimaging Research Branch, National Institute on Drug Abuse, National Institutes of Health, Baltimore, Maryland 21224
}

Deactivation of the human brain's default mode network (DMN) is regarded as suppression of endogenous activity to support exogenous task-related processes. This phenomenon has important functional relevance and insufficient DMN deactivation has been implicated in several neuropsychiatric disorders. However, the neurochemical mechanism of the DMN's deactivation remains largely unknown. In the present study, we test the hypothesis that the major excitatory and inhibitory neurotransmitters, glutamate and GABA, respectively, are associated with DMN deactivation. We used magnetic resonance spectroscopy to measure neurotransmitter concentrations in the posterior cingulate cortex/precuneus ( $\mathrm{PCC} / \mathrm{PCu}$ ), a key component of the DMN, and functional magnetic resonance imaging to evaluate DMN deactivation induced by an n-back working memory task. Our results demonstrate significant associations of glutamate and GABA with DMN deactivation. Specifically, high regional GABA concentration in the $\mathrm{PCC} / \mathrm{PCu}$ area is associated with enhanced deactivation induced by the task in the same region, whereas high glutamate concentration is associated with reduced deactivation. Furthermore, the association between GABA and DMN deactivation increases with the cognitive loads. These neurochemical characteristics of DMN deactivation may provide novel insights toward better understanding of the DMN's functions under normal physiological conditions and dysfunctions in neuropsychiatric disorders.

\section{Introduction}

Neuroimaging studies have demonstrated that, compared with the resting state, activity in a set of brain regions including the posterior cingulate cortex/precuneus $(\mathrm{PCC} / \mathrm{PCu})$, medial prefrontal cortex (mPFC), and hippocampus consistently decrease (termed as deactivation) during a wide range of tasks requiring external orientation (Shulman et al., 1997). These distributed brain regions were defined as the default mode network (DMN) by Raichle et al. (2001). DMN deactivation is thought to be associated with suppression of spontaneous brain activities and reallocation of resources to ongoing, attention-demanding tasks (McKiernan et al., 2003); therefore, the more demanding the task, the stronger the deactivation of the DMN tends to be (Singh and Fawcett, 2008). Furthermore, several studies have found that DMN deactivation is correlated with behavioral performance. For example, stronger deactivation of PCC in a working memory (WM) task predicts better performance (Anticevic et al., 2010). In contrast to DMN function in healthy participants, failure of DMN deactivation has been observed in psychiatric disorders such as schizophrenia (Whitfield-Gabrieli et al., 2009), Alzheimer's dis-

\footnotetext{
Received May 8, 2013; revised Oct. 1, 2013; accepted Oct. 4, 2013

Author contributions: Y.Y. designed research; Y.H., X.C., and H.G. performed research; Y.H., X.C., H.G., and Y.Y. analyzed data; Y.H., X.C., H.G., and Y.Y. wrote the paper.

This work was supported by the Intramural Research Program of the National Institute on Drug Abuse, National Institutes of Health. We thank Siemens Medical Solutions USA for providing an MEGA-PRESS sequence and Dr. Vani Pariyadath for help in manuscript preparation.

*Y.H., X.C., and H.G. contributed equally to this work.

The authors declare no competing financial interests.

Correspondence should be addressed to Yihong Yang, PhD, Neuroimaging Research Branch, National Institute on Drug Abuse, National Institutes of Health, Baltimore, MD 21224. E-mail: yihongyang@mail.nih.gov.

DOI:10.1523/JNEUROSCI.1973-13.2013

Copyright $\odot 2013$ the authors $\quad 0270-6474 / 13 / 3318566-08 \$ 15.00 / 0$
}

ease (Greicius et al., 2004), and autism (Kennedy et al., 2006). These findings indicate the importance of DMN deactivation contributing to both normal cognitive functions and psychiatric disorders. However, the underlying neurochemical mechanism of DMN deactivation remains largely unknown.

DMN deactivation has been well depicted by blood oxygen level-dependent (BOLD) imaging (Ogawa et al., 1990). Although influenced by multiple physiological and biophysical factors (Ogawa et al., 1993), BOLD signal has been found to be coupled with neural activity (Logothetis et al., 2001). Particularly, negative BOLD response has been found to associate with decreased neural activity (Stefanovic et al., 2004; Shmuel et al., 2006). At the cellular level, neuronal activity is regulated by multiple neurochemical processes including cycling of glutamate and GABA, the major excitatory and inhibitory neurotransmitters in the CNS. The coordination between glutamatergic neurons and GABAergic interneurons is believed to have a direct impact on BOLD contrast (Logothetis et al., 2001; Buzsáki et al., 2007). Congruent with this idea, previous studies have shown a negative correlation between GABA concentration and BOLD signals (Northoff et al., 2007; Stagg et al., 2011). A positive correlation between glutamate concentration and BOLD signal change has also been reported (Enzi et al., 2012). In addition, associations among glutamate, GABA, and functional connectivity have been reported (Kapogiannis et al., 2013). However, the coordinative effects of glutamate and GABA on task-induced BOLD change have so far not been well demonstrated.

By combining BOLD and magnetic resonance spectroscopy (MRS) techniques, the relationship between neurotransmitters and brain activation/deactivation can be examined at a system level. Based upon the findings mentioned above, we hypothe- 
a

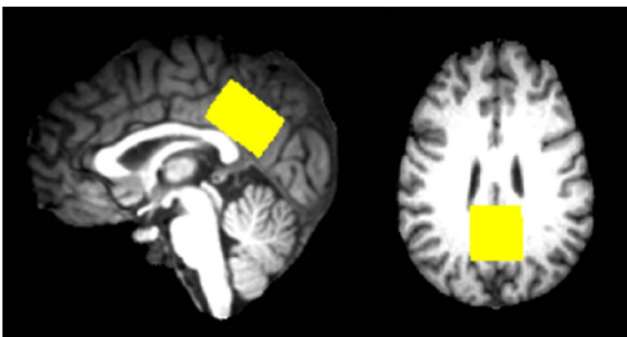

b

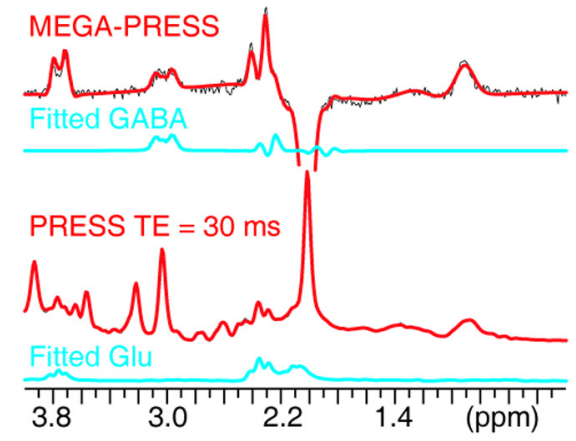

e

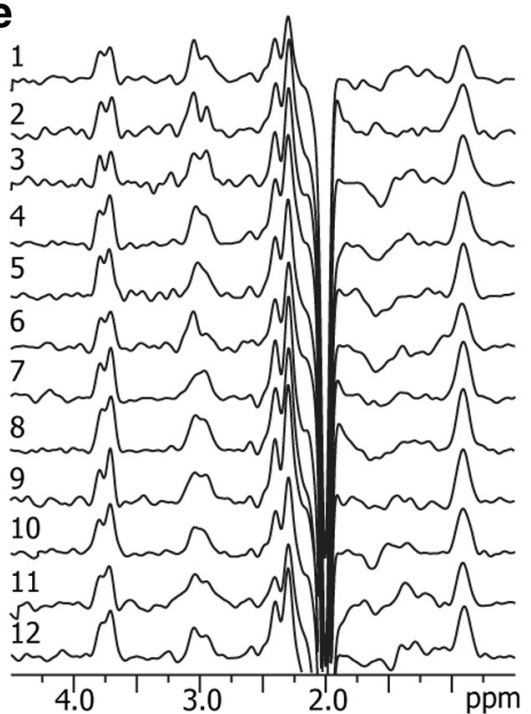

C

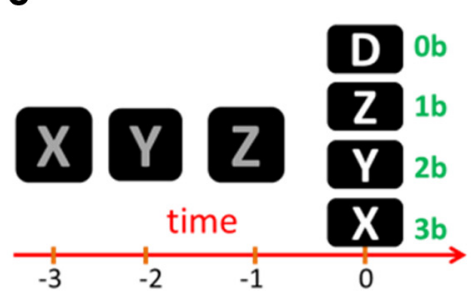

d

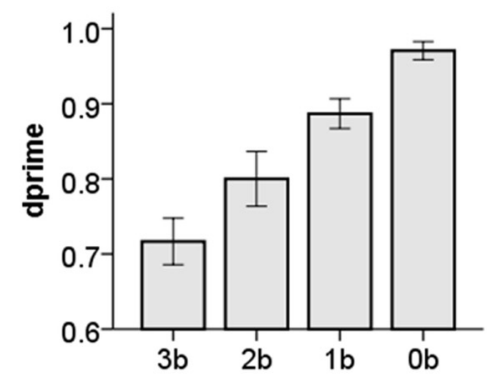

Figure 1. MRS and fMRI experiments. $\boldsymbol{a}, \mathrm{A}$ VOI was placed at the PCC/PCu for ${ }^{1} \mathrm{H}$ spectroscopy. $\boldsymbol{b}$, Regional GABA and glutamate concentrations were assessed using MRS techniques. $c$, An n-back working memory task was administered to probe the default mode network deactivation, with 0 -back as the control condition (time scale is $2 \mathrm{~s}$ ). $\boldsymbol{d}$, Behavioral performance (dprime) during the working memory task demonstrated a significant memory load effect. $\boldsymbol{e}$, Individual GABA spectra. A weighting function of Lorentzian-Gaussian transformation ( $\mathrm{lb}=-3 \mathrm{~Hz}, \mathrm{gb}=8 \mathrm{~Hz}$ ) was applied, and the displayed peak intensities were normalized to $\mathrm{N}$-acetylaspartic acid.

sized that DMN deactivation is associated with both excitatory and inhibitory neurotransmitters and the associations are dependent on cognitive load. To test this hypothesis, the present study examined the relationship between DMN deactivation induced by a WM task with different loads and the endogenous concentrations of glutamate and GABA in the PCC/PCu region. Positive and negative correlations with BOLD signals were expected for glutamate and GABA, respectively, in a load-dependent fashion.

\section{Materials and Methods}

Subjects. Twenty-four healthy subjects (age: $34.4 \pm 8.6$ years; 10 females) participated in the study. Subjects had no histories of neurological or psychiatric disorders and had no current or past drug abuse. The use of drugs that affect neurotransmitter levels or cortical inhibition and excitation was exclusionary for participants in this study. Participants were questioned about prescription medication and illicit drug use and under- went urine toxicology assessing the presence of prescription medications and drugs of abuse at their initial screening visit. They were also screened for drugs of abuse (urine toxicology) including benzodiazepines on the day of scanning. Before the experiment, all subjects provided written informed consent approved by the Institutional Review Board of the $\mathrm{Na}$ tional Institute on Drug Abuse.

MRS data acquisition and processing. MRS and fMRI scans were performed on a Siemens 3T Trio scanner using a 12-channel coil. The MRS experiments preceded the fMRI task. A $2.4 \times 3.2 \times 3.6 \mathrm{~cm}^{3}$ voxel of interest (VOI) was placed at the PCC/PCu (Fig. 1a) and a control region was placed at the primary visual cortex. The ${ }^{1} \mathrm{H}$ spectrum optimized for detecting GABA was acquired by a MEGA-PRESS sequence (Rothman et al., 1984; Mescher et al., 1998) with the following parameters: TE/TR $=$ $68 / 5000 \mathrm{~ms}$; number of average $=96$ (scan time $=8 \mathrm{~min}$ ). The editing pulses with a duration of $19.9 \mathrm{~ms}$ and a bandwidth of $45 \mathrm{~Hz}$ were applied alternatively at frequency of 1.9 or $7.5 \mathrm{ppm}$. There were two loops in the GABA sequence: the interleaving of edit on/off in the inner loop and the averaging in the outer loop. It has been reported in the literatures that PRESS with TE $\sim 30 \mathrm{~ms}$ achieves reliable glutamate detections (Mullins et al., 2008; Hancu, 2009). Therefore, the glutamate concentration was obtained by a PRESS sequence $(\mathrm{TE} / \mathrm{TR}=30 / 3000 \mathrm{~ms}$; number of average $=128$; scan time $=6 \mathrm{~min}$ ) from the same VOI. Field map shimming was performed before MRS scans to ensure the line-width of water $<14 \mathrm{~Hz}$. A VAPOR (VAriable pulse Power and Optimized Relaxation delays) module (Tkác et al., 1999) was used in both sequences to achieve water suppression. Spectra of water were also acquired from the same VOI using the same MEGA-PRESS and PRESS sequences without the water suppression module, respectively. The number of average of the water spectra was 16. All MRS data were quantified using LCModel (version 6.3-0D; Provencher, 1993, 2001; Fig. 1b). The LCModel assumes that the experimental spectrum can be fitted in the frequency domain by the linear combination of a group of basis sets, each of which is the frequency spectrum of a certain metabolite/ macromolecule $(\mathrm{MM})$, together with a baseline to compensate MM signals that the MM basis sets do not account for. The reliability of the measurement was indicated by the Cramer-Rao lower bounds (CRLB) and a commonly accepted CRLB criterion of $20 \%$ was chosen to reject low-quality spectra. Different basis sets from simulation were used for the MEGA-PRESS and PRESS quantifications. Both GABA and glutamate concentrations were referenced to the unsuppressed water concentration. The MRS signal of water is subject to different proton densities and $\mathrm{T} 1$ and $\mathrm{T} 2$ relaxation times in gray matter, white matter, and CSF. Therefore, the volume fractions of different tissue types were calculated by segmenting T1 images in SPM8. The water signal was then corrected by different tissue fractions and sensitivity factors in gray matter (0.92), white matter (0.81), and CSF (1.0) to account for the partial volume effect (Geramita et al., 2011). $\mathrm{T} 1$ and $\mathrm{T} 2$ values of $\mathrm{GABA}(\mathrm{T} 1=1310 \mathrm{~ms}, \mathrm{~T} 2=88 \mathrm{~ms}$ ) (Edden et al., 2012; Puts et al., 2013) and glutamate (T1 = 1270 ms, T2 = 181 ms) (Mlynárik et al., 2001; Ganji et al., 2012) were used for a global relaxation correction for absolute quantification in millimolar (mM).

Working memory task. Participants performed an n-back WM task (Owen et al., 2005) during a 14 min block design fMRI scan. The n-back 
task presented a single letter for $500 \mathrm{~ms}$, followed by an interstimulus interval of $1500 \mathrm{~ms}$ under four conditions: 0-back (0b), 1-back (1b), 2 -back ( $2 \mathrm{~b}$ ), and 3-back (3b). In the $0 \mathrm{~b}$ vigilance condition, participants were asked to respond with a button press to letter " $D$ "; in the $1 \mathrm{~b}$ condition, participants responded if the current letter was identical to the previous one; and in the $2 \mathrm{~b} / 3 \mathrm{~b}$ conditions, participants responded if the current letter was identical to the second/third previous one (Fig. 1c). The task scan included three runs and each run had eight blocks during which each condition $(0 \mathrm{~b}, 1 \mathrm{~b}, 2 \mathrm{~b}$, or $3 \mathrm{~b})$ was presented twice. There were 15 consecutive trials in each block (33\% targets). The $0 \mathrm{~b}$ block was placed at the beginning of each run and the order of $1 b, 2 b$, and $3 b$ blocks was counterbalanced. A $2 \mathrm{~s}$ visual instruction preceded each block to indicate the upcoming condition. The primary behavioral measurement of task performance at each task condition was dprime, estimated by the hit rate penalized by the false alarm rate (Haatveit et al., 2010). All subjects practiced a brief version of the n-back WM task outside the scanner before imaging.

fMRI data collection and preprocessing. A single-shot gradient-echo echo-planar imaging sequence was used to acquire BOLD images during the WM task scans. The imaging parameters were as follows: TR/TE = $2000 / 27 \mathrm{~ms} ; \mathrm{FA}=78^{\circ}$; slice thickness $=4 \mathrm{~mm}$ without gap; 39 slices; FOV $=220 \times 220 \mathrm{~mm}^{2}$ with in-plane resolution of $3.44 \times 3.44 \mathrm{~mm}^{2}$. To facilitate spatial normalization, an anatomical scan was acquired using a T1-weighted 3D magnetization prepared rapid gradient echo sequence $\left(256 \times 192 \times 208\right.$ matrix size; $1 \times 1 \times 1 \mathrm{~mm}^{3}$ spatial resolution; TI/TR/ $\mathrm{TE}=900 / 1900 / 3.51 \mathrm{~ms}$; flip angle $=9^{\circ}$ ).

Preprocessing steps for fMRI data included slice-timing correction, head motion correction, spatial smoothing with a $6 \mathrm{~mm}$ Gaussian kernel, and quadratic detrending. General linear models were constructed to obtain the task-evoked activation maps during the $1 \mathrm{~b}, 2 \mathrm{~b}$, and $3 \mathrm{~b} \mathrm{WM}$ task compared with the vigilant $0 \mathrm{~b}$ condition; the six motion parameters were included as covariates. The task activation maps were then normalized to standard Talairach and Tournoux space with a resampling resolution of $3 \times 3 \times 3 \mathrm{~mm}^{3}$ using nonlinear registration (Geng et al., 2009) to facilitate group analysis.

Statistical analyses. WM load effects on behavior performance (dprime) were assessed by repeated-measures ANOVA. The relationship between glutamate and GABA concentrations in the PCC/PCu and relationships of the two neurotransmitters with gender and age were examined by bivariate correlation analyses.

Whole brain voxelwise fMRI activation/deactivation patterns at the group level were evaluated by ANOVA. Specifically, contrast maps of $1 \mathrm{~b}$, $2 \mathrm{~b}$, and $3 \mathrm{~b}$ versus $0 \mathrm{~b}$ estimated from the first level analysis were modeled as three levels of the WM load. A threshold for significance was set to $p<$ 0.01 corrected for whole brain multiple comparisons based on Monte Carlo simulations, which corresponds to uncorrected $p<0.001$ and a minimum cluster size of $594 \mathrm{~mm}^{3}$. To examine brain deactivation in more detail, a region of interest (ROI) was defined in the PCC/PCu based on the main effect of WM task revealed from the whole brain voxelwise ANOVA analysis. A post hoc test on BOLD signal changes across different WM loads was performed. In addition, to explore the functional relevance of the PCC/PCu deactivation, correlation between the BOLD signal change in the $\mathrm{PCC} / \mathrm{PCu}$ and the task performance (dprime) was examined.

To assess how neurotransmitters exert influence on brain response to the WM task at different cognitive loads, a hierarchical regression procedure was performed to regress the PCC/PCu deactivation (BOLD signal change relative to $0 \mathrm{~b}$ ) on age, fraction of gray matter (GM), and glutamate and GABA concentrations, under conditions of $1 b, 2 b$, and $3 b$ separately. Age was included in the model because of its significant influence on the DMN deactivation (Grady et al., 2006; Spreng and Schacter, 2012). GM fraction was included because of its potential influence on the relationship between neurotransmitters and BOLD signal change. At the first step of regression (model 1), the PCC/PCu deactivation was predicted by a constant term, GM and age. At the second step (model 2), the $\mathrm{PCC} / \mathrm{PCu} \mathrm{GABA}$ and glutamate concentrations were added in. For a negative control purpose, the same regression procedures were performed by replacing GABA and glutamate concentrations from the PCC/ $\mathrm{PCu}$ with that from the visual primary cortex. Glutamine or Glx (the combination of glutamate and glutamine) was used to replace glutamate in the model 2 to construct two contrast models, which could be used to determine the unique excitatory profile of glutamate.

A previous study (Kapogiannis et al., 2013) suggested that glutamate and GABA measured from posterior medial cortex predict the resting state functional connectivity within the entire DMN. It would therefore be interesting to determine whether glutamate and GABA measured from the PCC/PCu region associate with the entire DMN deactivation. For this purpose, we did a complementary analysis. The DMN was defined as deactivated regions in the working memory task, mainly including mPFC, PCC/ $\mathrm{PCu}$, and bilateral parahippocampus. The same regression models used to examine the relationship between $\mathrm{PCC} / \mathrm{PCu}$ deactivation and neurotransmitters were performed to examine the relationship between the entire DMN deactivation and neurotransmitters.

\section{Results}

\section{Behavior}

WM load was found to modulate task performance as measured by dprime (Fig. $1 d ; F_{(3,69)}=30.78, p=0.0005$ ). Post hoc $t$ tests using Bonferroni correction for multiple comparisons determined that dprime was significantly different between each pair of the two conditions $(p<0.04)$.

\section{Glutamate and GABA levels in the PCC/PCu}

Individual GABA spectra are shown in Figure 1e. The full-width at half-maximum of the MEGA-PRESS and the $30 \mathrm{~ms}$ PRESS metabolite spectra measured by LCModel were $5.3 \pm 1.5$ and $5.2 \pm 1.2 \mathrm{~Hz}$, respectively. The fitting quality, which was quantified as the ratio of the maximum in the spectrum-minus-baseline to twice of the root mean square of the fitting residuals, of the MEGA-PRESS spectra was $45 \pm 8$ and that of 30 ms PRESS was $51 \pm 5$. The average CRLB of GABA was $9 \%$ (SD 1\%, range $7-11 \%$ ), that of glutamate was $5 \%$ (SD \%1, range $4-6 \%$ ). No subject was excluded by the criterion of CRLB. Glutamate and GABA concentrations in the PCC/PCu were $7.46 \pm 0.56$ and $1.82 \pm 0.20 \mathrm{~mm}$, respectively. Age was negatively correlated with glutamate $(r=-0.43, p=0.04)$, but not GABA $(p=0.18)$. No gender effect was found on glutamate or GABA concentration $(p>0.65)$. No correlation was found between glutamate and GABA concentrations $(p=0.84)$. In the MRS VOI, the fractional tissue composition was $56 \pm 5 \%$ for gray matter, $33 \pm 4 \%$ for white matter, and $11 \pm 3 \%$ for CSF.

\section{Brain activation/deactivation during the WM task}

Significant main effect of the WM task was shown in a number of brain regions. To illustrate activation and deactivation induced by the task, brain activities at the contrast of 3b-0b within these areas are displayed in Figure $2 a$. The task-induced positive activation regions included bilateral superior and inferior parietal lobules, middle and inferior frontal gyri, anterior insula, anterior cingulate cortex extending to supplementary motor area, thalamus, and precuneus. The task-induced deactivation regions were well overlapped with the DMN, including the PCC/PCu, mPFC, hippocampus, parahippocampal gyrus, superior temporal gyrus, and transverse temporal gyrus.

To elaborate on brain deactivation to the WM task, an ROI in the PCC/PCu was selected based on the main effect of the WM task at the significance level of $p<0.01$ (corrected for multiple comparisons), resulting in a volume of $12528 \mathrm{~mm}^{3}$ (Fig. $2 a$, arrows). A post hoc analysis revealed that the PCC/PCu deactivation was stronger under condition $2 \mathrm{~b}$ and $3 \mathrm{~b}$ than under condition $1 \mathrm{~b}$, but did not differ between condition $2 \mathrm{~b}$ and $3 \mathrm{~b}$ (Fig. 2b). The PCC/PCu deactivation was significantly correlated 


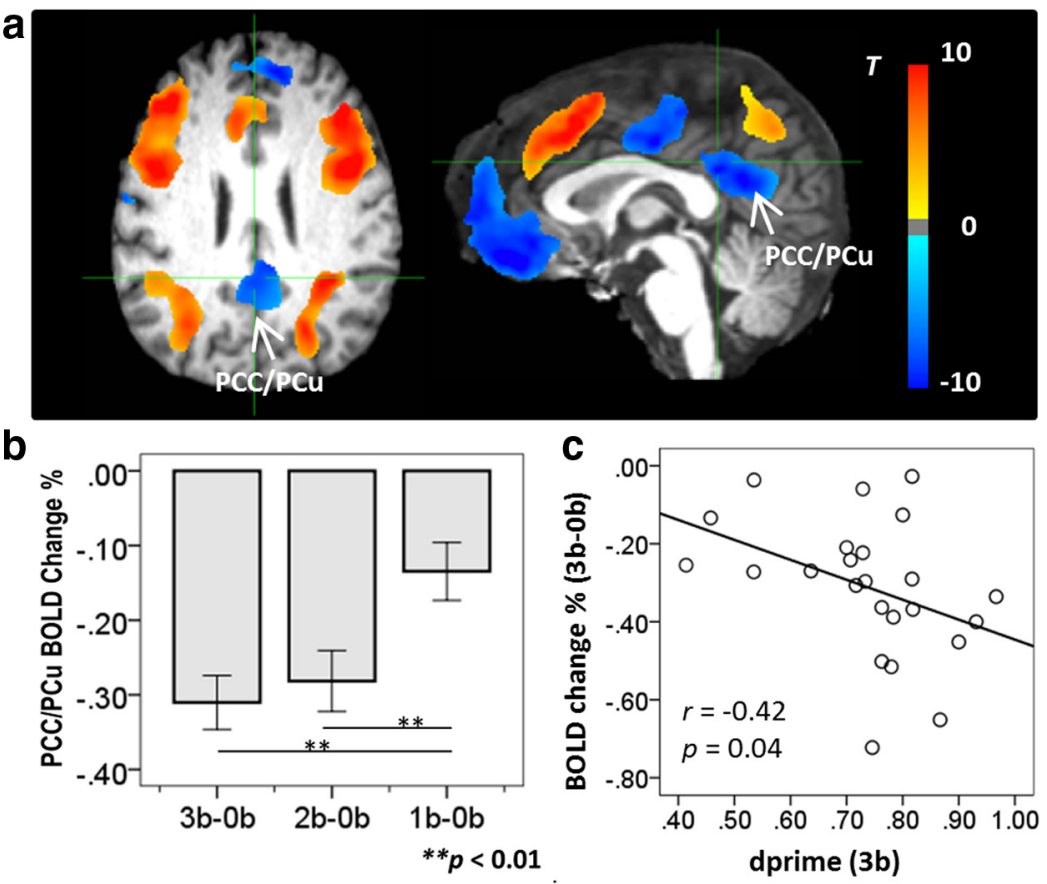

Figure 2. Brain activity during the working memory task. $\boldsymbol{a}$, Brain areas showing main effect of the working memory task revealed by voxelwise ANOVA (corrected $p<0.01$ ). To illustrate task-induced activation and deactivation, brain activities within these areas at the 3-back level are shown. $\boldsymbol{b}$, Cognitive load modulated deactivation in the PCC/PCu region. (c) The PCC/PCu deactivation was significantly correlated with 3-back working memory task performance.

with WM task performance as measured by dprime at condition $3 \mathrm{~b}(r=-0.42, p=0.04$; Fig. $2 c)$, but not at conditions $1 \mathrm{~b}$ and $2 \mathrm{~b}$.

\section{Glutamate and GABA levels modulate brain deactivation}

Hierarchical regression showed that the $\mathrm{PCC} / \mathrm{PCu}$ deactivation at low level of WM load could be predicted well by age (model 1). The prediction power, however, decreased when WM load increased. In contrast, after adding glutamate and GABA to the model (model 2), PCC/PCu deactivation could be predicted significantly at all levels of WM load (Fig. 3, Table 1). In addition, as revealed by coefficients of the regression models (Table 2), age demonstrated stable positive correlation with $\mathrm{PCC} / \mathrm{PCu}$ deactivation at all cognitive loads when controlling for glutamate and GABA $(p<0.002)$. The contribution of GABA increased considerably at higher cognitive load conditions. Furthermore, a follow-up analysis showed that GABA concentration correlated with the change in PCC/PCu deactivation from lower (1b) to high (3b) cognitive load conditions $(r=-0.39$, one-tailed $p=0.03)$. Glutamate $(5.44 \pm 0.72 \mathrm{~mm})$ and GABA $(1.98 \pm 0.22 \mathrm{~mm})$ concentrations in the control region did not show associations with the $\mathrm{PCC} / \mathrm{PCu}$ deactivation at any level of cognitive load in model 2 (coefficients significance, $p>0.45)$. In the PCC/PCu VOI, Glx significantly correlated with both glutamate $(r=0.696, p=0.0002)$ and glutamine $(r=$ $0.595, p=0.002)$, but there was no correlation between glutamate and glutamine $(r=-0.16, p=0.45)$. When glutamine was used to replace glutamate in model 2 , its regression coefficients were not significant ( $1 \mathrm{~b}: t=-1.084, p=0.29 ; 2 \mathrm{~b}: t=-1.18, p=0.25$; 3b: $t=-0.26, p=0.80)$. When Glx was used to replace glutamate in model 2 , its regression coefficients were not significant at $1 \mathrm{~b}$ and $2 \mathrm{~b}(1 \mathrm{~b}: t=1.56, p=0.13 ; 2 \mathrm{~b}: t=1.55, p=0.14)$ but was significant at $3 \mathrm{~b}(t=2.62, p=0.017)$.

Regressions on the entire DMN BOLD signal change demonstrated that the models including glutamate and GABA signifi- cantly explained more variations in the entire DMN BOLD signal change at all cognitive levels (1b: $p=0.046 ; 2 \mathrm{~b}: p=$ 0.04; 3b: $p=0.014$ ) compared with the models only including age and GM as predictors. The entire DMN deactivations were positively associated with glutamate $(1 \mathrm{~b}: t=$ $2.48, p=0.023 ; 2 \mathrm{~b}: t=2.10, p=0.049$; 3b: $t=2.06, p=0.054)$ and negatively with GABA (1b: $t=-1.66, p=0.113$; 2b: $t=$ $-2.27, p=0.035$; 3b: $t=-3.00, p=0.008)$. All of the DMN BOLD signal changes were also positively associated with age at all cognitive levels $(p<0.001)$. Therefore, their association patterns were consistent with those in the $\mathrm{PCC} / \mathrm{PCu}$ regression models (Fig. 3), with relatively smaller contributions of neurotransmitters but larger contribution of age.

\section{Discussion}

Task load modulation and functional relevance of the DMN

Consistent with previous studies (Esposito et al., 2006; Tomasi et al., 2006), we found significant modulation of cognitive load on deactivation in the PCC/PCu in present study. The deactivation of the DMN was interpreted as the suppression of ongoing brain activities related to internal thoughts (Raichle et al., 2001; Raichle and Snyder, 2007) when reallocating attentional resources from internal processes to goaldirected external stimuli (McKiernan et al., 2003). Behaviorally, task difficulty increased with the memory load, as reflected by reduced performance outcome at higher loads (Fig. 1d). Meanwhile, higher cognitive loads exerted stronger suppression of DMN (Fig. 2b). The DMN deactivation was found to be correlated with behavioral performance (Fig. $2 c, d$ ), suggesting a functional relevance to the DMN deactivation. The modulation of DMN deactivation by cognitive load may reflect the flexibility of dynamic neural resource configuration according to task demands.

\section{Gender and age effects}

We did not find an effect of gender on neurotransmitter concentrations in the present study, but previous reports on gender difference in GABA concentration were inconsistent (O'Gorman et al., 2011; Aufhaus et al., 2013). Because of this discrepancy, one may suspect that gender could confound the relationships between neurotransmitters and brain deactivation. To address this issue, we conducted another hierarchical regression adding gender as an independent variable. Our results indicated that gender did not contribute to the PCC/PCu deactivation significantly in any of the models $(p>0.26)$. Including gender also did not alter the relationships between neurotransmitters and $\mathrm{PCC} / \mathrm{PCu}$ deactivation.

In the present study we found that age was negatively correlated with DMN activity, which is consistent with previous studies (Lustig et al., 2003; Grady et al., 2006; Sambataro et al., 2010; Spreng and Schacter, 2012). An interesting observation in the present study is that the bivariate correlation between age and the DMN deactivation only holds at low cognitive load (1b), not at high load ( $2 \mathrm{~b}$ and $3 \mathrm{~b}$ ). However, their relationship becomes sta- 


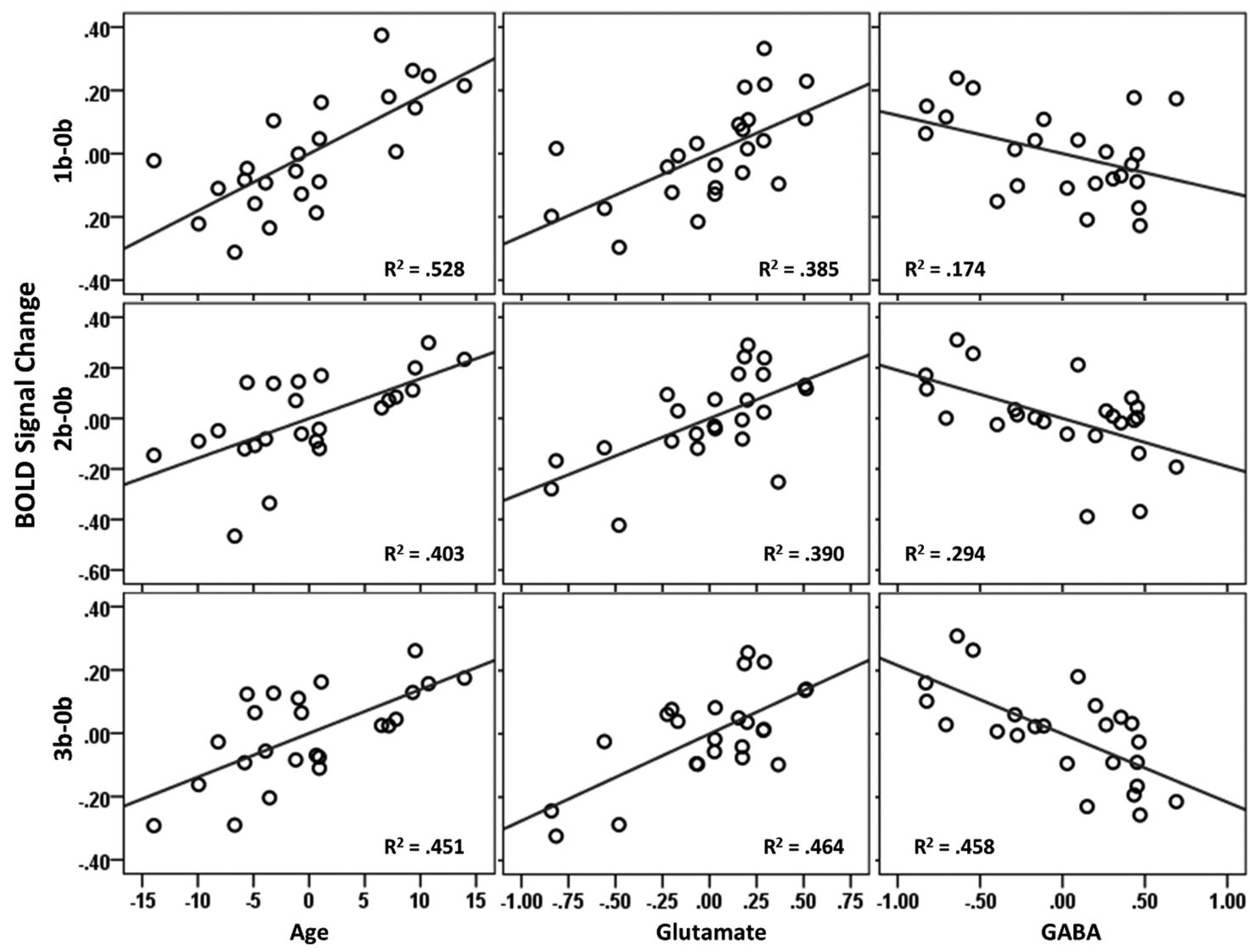

Figure 3. Partial regression plots. PCC/PCu deactivation can be predicted by age and regional glutamate and GABA concentrations assessed by MRS at resting state.

Table 1. Models to regress PCC/PCu BOLD signal on age, GM, glutamate, and GABA

\begin{tabular}{llllll}
\hline Model & $R^{2}$ & Adjusted $R^{2}$ & $\Delta R^{2}$ & $\Delta F$ & $p$ \\
\hline 1b & & & & & \\
1 & 0.297 & 0.230 & 0.297 & 4.428 & 0.025 \\
2 & 0.585 & 0.498 & 0.289 & 6.611 & 0.007 \\
2b & & & & & \\
1 & 0.132 & 0.049 & 0.132 & 1.593 & 0.227 \\
2 & 0.530 & 0.431 & 0.398 & 8.055 & 0.003 \\
3b & & & & & \\
1 & 0.095 & 0.009 & 0.095 & 1.107 & 0.349 \\
2 & 0.617 & 0.536 & 0.521 & 12.922 & 0.0003 \\
\hline
\end{tabular}

Model 1 predictors: (constant), age, GM; model 2 predictors: (constant), age, GM, glutamate, GABA; dependent variable: PCC/PCu BOLD signal change.

ble when controlling for glutamate and GABA concentrations. A plausible explanation is that glutamate and GABA may change with age and these changes may in turn result in changes in DMN activity. Conversely, the presence of the significant coefficients for age and neurotransmitters indicates their independent contributions to the variance of the task-induced deactivation. Ideally, age-related cognitive changes should be studied in an age range in which profound changes in cognition are expected. Whether the observed relationships in this study would hold in an aged population and how they link to age-related cognitive changes are interesting topics that warrant further investigation.

GABA/glutamate levels and neural activity

Our results are consistent with previous studies examining the effects of glutamate or GABA separately on BOLD signal change. The negative correlation between GABA concentration and $\mathrm{DMN}$ deactivation agrees with its profile as the major postsynap-
Table 2. Coefficients in regression models

\begin{tabular}{|c|c|c|c|c|}
\hline$\overline{\text { Model }}$ & Beta (SE) & Beta' & $t$ & $p$ \\
\hline \multicolumn{5}{|l|}{$1 \mathrm{~b}$} \\
\hline \multicolumn{5}{|l|}{1} \\
\hline Age & $0.013(0.004)$ & 0.574 & 2.844 & 0.010 \\
\hline GM & $0.344(0.857)$ & 0.081 & 0.402 & 0.692 \\
\hline \multicolumn{5}{|l|}{2} \\
\hline Age & $0.018(0.004)$ & 0.815 & 4.612 & 0.0002 \\
\hline GM & $-0.918(0.775)$ & -0.216 & -1.185 & 0.251 \\
\hline Glutamate & $0.261(0.076)$ & 0.640 & 3.446 & 0.003 \\
\hline GABA & $-0.121(0.060)$ & -0.321 & -2.003 & 0.060 \\
\hline \multicolumn{5}{|l|}{$2 b$} \\
\hline \multicolumn{5}{|l|}{1} \\
\hline Age & $0.009(0.005)$ & 0.382 & 1.704 & 0.103 \\
\hline GM & $0.237(1.004)$ & 0.053 & 0.236 & 0.816 \\
\hline \multicolumn{5}{|c|}{ 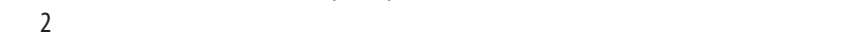 } \\
\hline Age & $0.016(0.004)$ & 0.674 & 3.583 & 0.002 \\
\hline GM & $-1.262(0.870)$ & -0.282 & -1.451 & 0.163 \\
\hline Glutamate & $0.297(0.085)$ & 0.690 & 3.489 & 0.002 \\
\hline GABA & $-0.190(0.068)$ & -0.480 & -2.812 & 0.011 \\
\hline \multicolumn{5}{|l|}{$3 b$} \\
\hline \multicolumn{5}{|l|}{1} \\
\hline Age & $0.007(0.005)$ & 0.337 & 1.473 & 0.156 \\
\hline GM & $0.735(0.905)$ & 0.186 & 0.812 & 0.426 \\
\hline \multicolumn{5}{|l|}{2} \\
\hline Age & $0.014(0.004)$ & 0.670 & 3.947 & 0.001 \\
\hline GM & $-0.702(0.694)$ & -0.178 & -1.012 & 0.324 \\
\hline Glutamate & $0.275(0.068)$ & 0.724 & 4.053 & 0.0007 \\
\hline GABA & $-0.216(0.054)$ & -0.617 & -4.004 & 0.0008 \\
\hline
\end{tabular}

Dependent variable: PCC/PCu deactivation during WM task; model 1 predictors: (constant), age, GM; model 2 predictors: (constant), age, GM, glutamate, GABA.

Beta (SE), unstandardized coefficient (SE); and beta', standardized coefficient. 
tic inhibitory neurotransmitter. The relationship between GABA and BOLD signal is highly accordant across different studies (Northoff et al., 2007; Muthukumaraswamy et al., 2009; Sumner et al., 2010). In addition to its association with the magnitude of BOLD signal, the GABA concentration was found to correlate with the latency and width of the stimulus-evoked HRF curve (Muthukumaraswamy et al., 2012), as well as electroencephalogram measures (Muthukumaraswamy et al., 2009; Rowland et al., 2013). In contrast to the suppression effect of GABA, the glutamate concentration has been found to be positively correlated with BOLD signal change. For example, when only controlling for age, regional glutamate concentration in perigenual anterior cingulate cortex (a part of DMN) was found to be positively correlated with task-induced deactivation (Enzi et al., 2012) and task-induced activation in supragenual anterior cingulate cortex (Duncan et al., 2011). Similarly, resting-state glutamate concentration in the dorsal anterior cingulate cortex (dACC) could predict the strength of the BOLD response to a task requiring cognitive control, not just in the dACC but also in other distinct brain regions including the retrosplenial cortex and inferior parietal lobule (both are considered as parts of DMN; Falkenberg et al., 2012). These results showed convincing evidence for the direct relevance between neurotransmitters and BOLD contrast. In the present study, we revealed significant coordinative effects of glutamate and GABA on task-induced BOLD signal change in $\mathrm{PCC} / \mathrm{PCu}$. We further demonstrated significant associations between PCC/PCu neurotransmitters and the entire DMN deactivation, suggesting that regional neurotransmitter profile in the hub of a network may significantly affect the activity of the whole network, possibly through functional connectivity (Kapogiannis et al., 2013).

The system-level coordinative effects of glutamate and GABA concentrations on the DMN deactivation may involve complex cellular processes. It might be reasonable to assume that high regional GABA concentrations could facilitate inhibition of local neural activities through GABAergic interneurons, resulting in stronger brain deactivation. Similarly, high regional glutamate concentrations could promote excitation of local glutamatergic neurons. In the resting state, glutamatergic and GABAergic activities in the DMN may reach equilibrium to facilitate endogenous processes. When turning from the resting to a task state, the DMN suppression might be achieved by enhancing GABAergic activities to regulate glutamatergic activities. Therefore, individuals with a higher GABA/glutamate ratio tend to suppress ongoing neural activities more efficiently. Furthermore, because the inhibition of glutamatergic neurons might also decrease the probability of excitation of their downstream neurons, the inhibitory associations with GABA would be enhanced in these individuals.

\section{Implications of abnormal DMN deactivation and neurotransmitters in mental disease}

The associations between neurotransmitters and the DMN deactivation found in the present study may have important implications for neuropsychiatric disease. The DMN is suggested to be a fundamental brain network underlying normal and abnormal brain functions (Buckner et al., 2008; Anticevic et al., 2012). In contrast to the DMN deactivation patterns seen in healthy subjects, insufficient DMN deactivation has been observed in several psychiatric disorders. These studies suggest that the DMN abnormalities observed in fMRI studies may be closely associated with neuropsychiatric disorders. Meanwhile, abnormal neurotransmitter function has been reported in disease populations, espe- cially in schizophrenia (Marsman et al., 2013). Our results indicate that coordination of glutamate and GABA is associated with task-induced DMN deactivation. Abnormal DMN deactivation in neuropsychiatric disorders may be associated with an imbalance of glutamate and GABA neurotransmitters. Further assessment of the relationships among clinical observations, activity, and neurotransmitter function of the DMN in such patient populations may provide useful insights into these diseases.

\section{Limitations}

We observed associations of local glutamate and GABA concentrations at resting state with task-induced BOLD signal change in the same region. However, as a distributed system, activity of one brain region is influenced by many other regions. Specifically, release of neurotransmitters could depend on remote afferent projections, which cannot be determined in the present study. Consideration of both remote afferent projections and local neurotransmitters would produce better models to predict BOLD signal change.

Technically, measurements of GABA and glutamate are challenging. The MM coediting is an important issue for the GABA detection using editing sequences, and the degree of MM signal contamination varies with sequences and parameters (Henry et al., 2001; Terpstra et al., 2002; Near et al., 2011). Nevertheless, previous studies (Hofmann et al., 2001; Mader et al., 2002) suggested that the MM concentrations in cortical regions of healthy adults are very stable with respect to age and gender. Therefore, individual differences in the contaminated GABA levels may reflect primarily the differences in the GABA itself (Donahue et al., 2010). In addition, the degree to which glutamate and glutamine can be separated at $3 \mathrm{~T}$ is arguable. In the present study, the CRLBs of glutamate and glutamine fitting from LCModel were $5 \pm 1 \%$ and $14 \pm 2 \%$, respectively, suggesting that both are quantifiable. Another limitation of glutamate measurement with ${ }^{1} \mathrm{H}$-MRS is its inability to distinguish signals between metabolic and neurotransmitter pools. However, the relationship between neuronal glucose oxidation and glutamate/glutamine cycling is suggested to be linear (de Graaf et al., 2004), which supports the assumption that the total glutamate level measured by ${ }^{1} \mathrm{H}$-MRS could be a reasonable metric of glutamate involve in glutamatergic neurotransmission.

In the present study, fMRI and MRS data were collected separately. It would be interesting to assess the association between neurotransmitter levels and brain activity at the same functional states. In addition, the influence of the menstrual cycle on the cerebral GABA and glutamate levels could be region specific (Epperson et al., 2002; Batra et al., 2008; Harada et al., 2011). However, as far as we know, there have been no reports about GABA or glutamate level changes in PCC/PCu across the menstrual cycle. This is a factor that we did not control for in the present study.

\section{Summary}

In conclusion, the present study demonstrates significant association between neurotransmitters and the DMN deactivation probed by a WM task. The major excitatory neurotransmitter, glutamate, prevents BOLD signal from deactivation, whereas GABA, the major inhibitory neurotransmitter, exerts the opposite effects. These neurochemical characteristics of DMN deactivation may provide novel insights into the function of DMN in healthy individuals and its dysfunction in brain disorders.

\section{Notes}

Supplemental material for this article is available at http://irp.drugabuse. gov/PDFs/supp/supHu08282013.pdf. This supplemental material docu- 
ment includes: (1) individual GABA spectra, (2) an estimation of GABAmacromolecule contamination and glutamate-glutamine separation, and (3) relationships between the entire DMN deactivation and neurotransmitters. This material has not been peer reviewed.

\section{References}

Anticevic A, Repovs G, Shulman GL, Barch DM (2010) When less is more: TPJ and default network deactivation during encoding predicts working memory performance. Neuroimage 49:2638-2648. CrossRef Medline

Anticevic A, Cole MW, Murray JD, Corlett PR, Wang XJ, Krystal JH (2012) The role of default network deactivation in cognition and disease. Trends Cogn Sci 16:584-592. CrossRef Medline

Aufhaus E, Weber-Fahr W, Sack M, Tunc-Skarka N, Oberthuer G, Hoerst M, Meyer-Lindenberg A, Boettcher U, Ende G (2013) Absence of changes in GABA concentrations with age and gender in the human anterior cingulate cortex: A MEGA-PRESS study with symmetric editing pulse frequencies for macromolecule suppression. Magn Reson Med 69:317320. CrossRef Medline

Batra NA, Seres-Mailo J, Hanstock C, Seres P, Khudabux J, Bellavance F, Baker G, Allen P, Tibbo P, Hui E, Le Melledo JM (2008) Proton magnetic resonance spectroscopy measurement of brain glutamate levels in premenstrual dysphoric disorder. Biol Psychiatry 63:1178-1184. CrossRef Medline

Buckner RL, Andrews-Hanna JR, Schacter DL (2008) The brain's default network. Ann N Y Acad Sci 1124:1-38. CrossRef Medline

Buzsáki G, Kaila K, Raichle M (2007) Inhibition and brain work. Neuron 56:771-783. CrossRef Medline

de Graaf RA, Mason GF, Patel AB, Rothman DL, Behar KL (2004) Regional glucose metabolism and glutamatergic neurotransmission in rat brain in vivo. Proc Natl Acad Sci U S A 101:12700-12705. CrossRef Medline

Donahue MJ, Near J, Blicher JU, Jezzard P (2010) Baseline GABA concentration and fMRI response. Neuroimage 53:392-398. CrossRef Medline

Duncan NW, Enzi B, Wiebking C, Northoff G (2011) Involvement of glutamate in rest-stimulus interaction between perigenual and supragenual anterior cingulate cortex: a combined fMRI-MRS study. Hum Brain Mapp 32:2172-2182. CrossRef Medline

Edden RA, Intrapiromkul J, Zhu H, Cheng Y, Barker PB (2012) Measuring T2 in vivo with J-difference editing: Application to GABA at 3 Tesla. J Magn Reson Imaging 35:229-234. CrossRef Medline

Enzi B, Duncan NW, Kaufmann J, Tempelmann C, Wiebking C, Northoff G (2012) Glutamate modulates resting state activity in the perigenual anterior cingulate cortex-a combined fMRI-MRS study. Neuroscience 227: 102-109. CrossRef Medline

Epperson CN, Haga K, Mason GF, Sellers E, Gueorguieva R, Zhang W, Weiss E, Rothman DL, Krystal JH (2002) Cortical $\gamma$-aminobutyric acid levels across the menstrual cycle in healthy women and those with premenstrual dysphoric disorder: A proton magnetic resonance spectroscopy study. Arch Gen Psychiatry 59:851-858. CrossRef Medline

Esposito F, Bertolino A, Scarabino T, Latorre V, Blasi G, Popolizio T, Tedeschi G, Cirillo S, Goebel R, Di Salle F (2006) Independent component model of the default-mode brain function: assessing the impact of active thinking. Brain Res Bull 70:263-269. CrossRef Medline

Falkenberg LE, Westerhausen R, Specht K, Hugdahl K (2012) Resting-state glutamate level in the anterior cingulate predicts blood-oxygen leveldependent response to cognitive control. Proc Natl Acad Sci U S A 109: 5069-5073. CrossRef Medline

Ganji SK, Banerjee A, Patel AM, Zhao YD, Dimitrov IE, Browning JD, Brown ES, Maher EA, Choi C (2012) T2 measurement of J-coupled metabolites in the human brain at 3T. NMR Biomed 25:523-529. CrossRef Medline

Geng X, Christensen GE, Gu H, Ross TJ, Yang Y (2009) Implicit referencebased group-wise image registration and its application to structural and functional MRI. Neuroimage 47:1341-1351. CrossRef Medline

Geramita M, van der Veen JW, Barnett AS, Savostyanova AA, Shen J, Weinberger DR, Marenco S (2011) Reproducibility of prefrontal $\gamma$-aminobutyric acid measurements with J-edited spectroscopy. NMR Biomed 24:1089-1098. CrossRef Medline

Grady CL, Springer MV, Hongwanishkul D, McIntosh AR, Winocur G (2006) Age-related changes in brain activity across the adult lifespan. J Cogn Neurosci 18:227-241. CrossRef Medline

Greicius MD, Srivastava G, Reiss AL, Menon V (2004) Default-mode network activity distinguishes Alzheimer's disease from healthy aging: evi- dence from functional MRI. Proc Natl Acad Sci U S A 101:4637-4642. CrossRef Medline

Haatveit BC, Sundet K, Hugdahl K, Ueland T, Melle I, Andreassen OA (2010) The validity of $d$ prime as a working memory index: results from the "Bergen n-back task." J Clin Exp Neuropsychol 32:871-880. CrossRef Medline

Hancu I (2009) Optimized glutamate detection at 3T. J Magn Reson Imaging 30:1155-1162. CrossRef Medline

Harada M, Kubo H, Nose A, Nishitani H, Matsuda T (2011) Measurement of variation in the human cerebral GABA level by in vivo MEGA-editing proton MR spectroscopy using a clinical $3 \mathrm{~T}$ instrument and its dependence on brain region and the female menstrual cycle. Hum Brain Mapp 32:828-833. CrossRef Medline

Henry PG, Dautry C, Hantraye P, Bloch G (2001) Brain GABA editing without macromolecule contamination. Magn Reson Med 45:517-520. CrossRef Medline

Hofmann L, Slotboom J, Boesch C, Kreis R (2001) Characterization of the macromolecule baseline in localized $1 \mathrm{H}-\mathrm{MR}$ spectra of human brain. Magn Reson Med 46:855-863. CrossRef Medline

Kapogiannis D, Reiter DA, Willette AA, Mattson MP (2013) Posteromedial cortex glutamate and GABA predict intrinsic functional connectivity of the default mode network. Neuroimage 64:112-119. CrossRef Medline

Kennedy DP, Redcay E, Courchesne E (2006) Failing to deactivate: Resting functional abnormalities in autism. Proc Natl Acad Sci U S A 103:82758280. CrossRef Medline

Logothetis NK, Pauls J, Augath M, Trinath T, Oeltermann A (2001) Neurophysiological investigation of the basis of the fMRI signal. Nature 412: 150-157. CrossRef Medline

Lustig C, Snyder AZ, Bhakta M, O'Brien KC, McAvoy M, Raichle ME, Morris JC, Buckner RL (2003) Functional deactivations: change with age and dementia of the Alzheimer type. Proc Natl Acad Sci U S A 100:1450414509. CrossRef Medline

Mader I, Seeger U, Karitzky J, Erb M, Schick F, Klose U (2002) Proton magnetic resonance spectroscopy with metabolite nulling reveals regional differences of macromolecules in normal human brain. J Magn Reson Imaging 16:538-546. CrossRef Medline

Marsman A, van den Heuvel MP, Klomp DW, Kahn RS, Luijten PR, Hulshoff Pol HE (2013) Glutamate in schizophrenia: a focused review and metaanalysis of 1H-MRS studies. Schizophr Bull 39:120-129. CrossRef Medline

McKiernan KA, Kaufman JN, Kucera-Thompson J, Binder JR (2003) A parametric manipulation of factors affecting task-induced deactivation in functional neuroimaging. J Cogn Neurosci 15:394-408. CrossRef Medline

Mescher M, Merkle H, Kirsch J, Garwood M, Gruetter R (1998) Simultaneous in vivo spectral editing and water suppression. NMR Biomed 11:266272. CrossRef Medline

Mlynárik V, Gruber S, Moser E (2001) Proton T1 and T2 relaxation times of human brain metabolites at 3 Tesla. NMR Biomed 14:325-331. CrossRef Medline

Mullins PG, Chen H, Xu J, Caprihan A, Gasparovic C (2008) Comparative reliability of proton spectroscopy techniques designed to improve detection of J-coupled metabolites. Magn Reson Med 60:964-969. CrossRef Medline

Muthukumaraswamy SD, Edden RA, Jones DK, Swettenham JB, Singh KD (2009) Resting GABA concentration predicts peak gamma frequency and fMRI amplitude in response to visual stimulation in humans. Proc Natl Acad Sci U S A 106:8356-8361. CrossRef Medline

Muthukumaraswamy SD, Evans CJ, Edden RA, Wise RG, Singh KD (2012) Individual variability in the shape and amplitude of the BOLD-HRF correlates with endogenous GABAergic inhibition. Hum Brain Mapp 33: 455-465. CrossRef Medline

Near J, Simpson R, Cowen P, Jezzard P (2011) Efficient $\gamma$-aminobutyric acid editing at $3 \mathrm{~T}$ without macromolecule contamination: MEGASPECIAL. NMR Biomed 24:1277-1285. CrossRef Medline

Northoff G, Walter M, Schulte RF, Beck J, Dydak U, Henning A, Boeker H, Grimm S, Boesiger P (2007) GABA concentrations in the human anterior cingulate cortex predict negative BOLD responses in fMRI. Nat Neurosci 10:1515-1517. CrossRef Medline

Ogawa S, Lee TM, Kay AR, Tank DW (1990) Brain magnetic resonance imaging with contrast dependent on blood oxygenation. Proc Natl Acad Sci U S A 87:9868-9872. CrossRef Medline 
Ogawa S, Menon RS, Tank DW, Kim SG, Merkle H, Ellermann JM, Ugurbil K (1993) Functional brain mapping by blood oxygenation level-dependent contrast magnetic resonance imaging-a comparison of signal characteristics with a biophysical model. Biophys J 64:803-812. CrossRef Medline

O'Gorman RL, Michels L, Edden RA, Murdoch JB, Martin E (2011) In vivo detection of GABA and glutamate with MEGA-PRESS: reproducibility and gender effects. J Magn Reson Imaging 33:1262-1267. CrossRef Medline

Owen AM, McMillan KM, Laird AR, Bullmore E (2005) N-back working memory paradigm: a meta-analysis of normative functional neuroimaging studies. Hum Brain Mapp 25:46-59. CrossRef Medline

Provencher SW (1993) Estimation of metabolite concentrations from localized in vivo proton NMR spectra. Magn Reson Med 30:672-679. CrossRef Medline

Provencher SW (2001) Automatic quantitation of localized in vivo $1 \mathrm{H}$ spectra with LCModel. NMR Biomed 14:260-264. CrossRef Medline

Puts NA, Barker PB, Edden RA (2013) Measuring the longitudinal relaxation time of GABA in vivo at 3 tesla. J Magn Reson Imaging 37:999-1003. CrossRef Medline

Raichle ME, Snyder AZ (2007) A default mode of brain function: a brief history of an evolving idea. Neuroimage 37:1083-1090; discussion 1097-9. CrossRef Medline

Raichle ME, MacLeod AM, Snyder AZ, Powers WJ, Gusnard DA, Shulman GL (2001) A default mode of brain function. Proc Natl Acad Sci U S A 98:676-682. CrossRef Medline

Rothman DL, Behar KL, Hetherington HP, Shulman RG (1984) Homonuclear $1 \mathrm{H}$ double-resonance difference spectroscopy of the rat brain in vivo. Proc Natl Acad Sci U S A 81:6330-6334. CrossRef Medline

Rowland LM, Edden RA, Kontson K, Zhu H, Barker PB, Hong LE (2013) GABA predicts inhibition of frequency-specific oscillations in schizophrenia. J Neuropsychiatry Clin Neurosci 25:83-87. CrossRef Medline

Sambataro F, Murty VP, Callicott JH, Tan HY, Das S, Weinberger DR, Mattay VS (2010) Age-related alterations in default mode network: impact on working memory performance. Neurobiol Aging 31:839-852. CrossRef Medline

Shmuel A, Augath M, Oeltermann A, Logothetis NK (2006) Negative func- tional MRI response correlates with decreases in neuronal activity in monkey visual area V1. Nat Neurosci 9:569-577. CrossRef Medline

Shulman GL, Fiez JA, Corbetta M, Buckner RL, Miezin FM, Raichle ME, Petersen SE (1997) Common blood flow changes across visual tasks: II. decreases in cerebral cortex. J Cogn Neurosci 9:648-663. CrossRef Medline

Singh KD, Fawcett IP (2008) Transient and linearly graded deactivation of the human default-mode network by a visual detection task. Neuroimage 41:100-112. CrossRef Medline

Spreng RN, Schacter DL (2012) Default network modulation and largescale network interactivity in healthy young and old adults. Cereb Cortex 22:2610-2621. CrossRef Medline

Stagg CJ, Bachtiar V, Johansen-Berg H (2011) The role of GABA in human motor learning. Curr Biol 21:480-484. CrossRef Medline

Stefanovic B, Warnking JM, Pike GB (2004) Hemodynamic and metabolic responses to neuronal inhibition. Neuroimage 22:771-778. CrossRef Medline

Sumner P, Edden RA, Bompas A, Evans CJ, Singh KD (2010) More GABA, less distraction: a neurochemical predictor of motor decision speed. Nat Neurosci 13:825-827. CrossRef Medline

Terpstra M, Ugurbil K, Gruetter R (2002) Direct in vivo measurement of human cerebral GABA concentration using MEGA-editing at 7 Tesla. Magn Reson Med 47:1009-1012. CrossRef Medline

Tkác I, Starcuk Z, Choi IY, Gruetter R (1999) In vivo 1H NMR spectroscopy of rat brain at $1 \mathrm{~ms}$ echo time. Magn Reson Med 41:649-656. CrossRef Medline

Tomasi D, Ernst T, Caparelli EC, Chang L (2006) Common deactivation patterns during working memory and visual attention tasks: an intrasubject fMRI study at 4 Tesla. Hum Brain Mapp 27:694-705. CrossRef Medline

Whitfield-Gabrieli S, Thermenos HW, Milanovic S, Tsuang MT, Faraone SV, McCarley RW, Shenton ME, Green AI, Nieto-Castanon A, LaViolette P, Wojcik J, Gabrieli JD, Seidman LJ (2009) Hyperactivity and hyperconnectivity of the default network in schizophrenia and in first-degree relatives of persons with schizophrenia. Proc Natl Acad Sci U S A 106:1279-1284. CrossRef Medline 